\title{
Multi-Objective Dynamic Optimization for Optimal Load-following of Natural Gas Combined Cycle Power Plants under Stress Constraints
}

Yifan Wang, Debangsu Bhattacharyya*, Richard Turton

Department of Chemical and Biomedical Engineering, West Virginia University, Morgantown, WV 26506, USA 


\section{Gas turbine dynamic model}

Gas turbine dimensionless performance curves are used to model the dimensionless head and isentropic efficiency vs. dimensionless flow under standard conditions as shown in eqs S.1-S.5.

$$
\begin{gathered}
\dot{H}_{D}=\frac{\dot{H}}{\dot{H}_{T}} \\
\eta_{D}=\frac{\eta}{\eta_{T}} \\
\dot{V}_{D}=\frac{\dot{V}}{\dot{V}_{T}} \\
\dot{H}_{D}=a_{1} \dot{V}_{D}^{2}+a_{2} \dot{V}_{D}+a_{3} \\
\eta_{D}=b_{1} \dot{V}_{D}^{2}+b_{2} \dot{V}_{D}+b_{3}
\end{gathered}
$$

where $\dot{H}$ is the head, $\eta$ is the isentropic efficiency, and $\dot{V}$ is the volumetric flow rate under standard condition. The subscripts $D$ and $T$ represent dimensionless ratio and nominal condition, respectively.

Coefficients $a$ and $b$ have been shown in Table S1.

Table S1. Coefficients for the dimensionless GT performance curves

\begin{tabular}{|c|c|c|c|c|c|c|}
\hline Coefficients & a1 & a2 & a3 & b1 & b2 & b3 \\
\hline Results & -0.2108 & 0.4828 & 0.7277 & -0.4426 & 0.8875 & 0.5466 \\
\hline
\end{tabular}


Heat recovery steam generator (HRSG) in the NGCC plant

Table S2. Operating parameters and the surface area of the three-pressure HRSG

\begin{tabular}{|c|c|c|c|c|c|c|c|}
\hline \multicolumn{2}{|c|}{ Heating Section } & $\begin{array}{c}\text { Flue Gas } \\
\text { Inlet (K) }\end{array}$ & $\begin{array}{c}\text { Flue Gas } \\
\text { Outlet (K) }\end{array}$ & $\begin{array}{c}\text { Water/Steam } \\
\text { Inlet (K) }\end{array}$ & $\begin{array}{c}\text { Water/Steam } \\
\text { Outlet (K) }\end{array}$ & $\begin{array}{c}\text { Heat Duty } \\
(\mathrm{MW})\end{array}$ & $\begin{array}{c}\text { Area } \\
\left(\mathrm{m}^{2}\right)\end{array}$ \\
\hline \multirow{3}{*}{ PRE } & HTR 1 & 429.1 & 376.4 & 311.3 & 395.4 & 57.80 & 21,895 \\
\cline { 2 - 9 } & HTR 2 & 445.9 & 429.1 & 395.4 & 421.9 & 18.52 & 11,234 \\
\hline \multirow{3}{*}{ LP } & ECO & 446.9 & 445.9 & 422.0 & 428.7 & 1.10 & 827 \\
\cline { 2 - 9 } & EVA & 518.0 & 446.9 & 427.6 & 427.6 & 79.11 & 34,983 \\
\cline { 2 - 9 } & SH & 648.4 & 551.1 & 427.6 & 552.5 & 10.23 & 11,052 \\
\hline \multirow{4}{*}{ IP } & ECO & 549.5 & 518.7 & 423.6 & 534.0 & 0.68 & 847 \\
\cline { 2 - 9 } & EVA & 551.6 & 549.5 & 530.3 & 530.3 & 2.40 & 1,765 \\
\cline { 2 - 9 } & SH & 799.1 & 725.6 & 530.3 & 760.9 & 0.89 & 1,170 \\
\cline { 2 - 9 } & RH & 879.6 & 799.0 & 630.3 & 842.4 & 61.55 & 20,100 \\
\hline \multirow{4}{*}{ HP } & ECO1 & 549.5 & 518.0 & 425.5 & 490.4 & 34.67 & 7,471 \\
\cline { 2 - 9 } & ECO2 & 648.4 & 551.6 & 490.4 & 633.1 & 100.26 & 44,467 \\
\cline { 2 - 9 } & EVA & 725.4 & 648.4 & 632.5 & 632.5 & 89.79 & 29,295 \\
\cline { 2 - 9 } & SH1 & 799.1 & 725.4 & 632.5 & 750.0 & 86.60 & 21,104 \\
\cline { 2 - 9 } & SH2 & 879.6 & 799.3 & 746.1 & 841.7 & 35.59 & 15,800 \\
\hline
\end{tabular}




\section{Stress concentration factor calculation at shell-branch junction Position A}

Thermal stress concentration factor $\lambda_{t}$ and mechanical stress concentration factor $\lambda_{m}$ at shell-

branch junction Position A are given in EN 12952-320.

$$
\begin{gathered}
\lambda_{t}=\left\{\left[2-\frac{h+2700}{h+1700} Z+\frac{h}{h+1700}\left(\exp ^{-7 z}-1\right)\right]^{2}+0.81 z^{2}\right\}^{1 / 2} \\
z=\frac{d_{m b}}{d_{m}} \\
\lambda_{m}=2.2+\exp ^{W} \times X^{Q} \\
\mathrm{~W}=-1.14\left(\frac{s_{b}}{s}\right)^{2}-0.89\left(\frac{s_{b}}{s}\right)+1.43 \\
Q=0.326\left(\frac{s_{b}}{s}\right)^{2}-0.59\left(\frac{s_{b}}{s}\right)+1.08 \\
X=\frac{d_{m b}}{d_{m}} \sqrt{\frac{d_{m}}{2 s}}
\end{gathered}
$$

In eqs S.6-S.11, $d_{m b}$ is mean diameter of branch, $d_{m}$ is mean diameter of shell, $s_{b}$ is branch wall thickness, $s$ is shell wall thickness, and h is heat transfer coefficient. $Z, W, Q$ and $X$ are parameters for thermal/mechanical stress concentration factor. 


\section{Maximum allowable cycle number $N_{A}$ calculation}

$N_{A}$ is the maximum allowable cycle number under a certain stress range $\Delta \sigma$ with consideration

of the safety factors in EN 12952-320. Therefore, $N_{A, i}$ is evaluated according to the fatigue curves of ferritic rolled or forged steels with the different safety factor $s_{i}$.

$$
\Delta \sigma_{r, i}=0.8 R_{m}+\left(173150-0.8 R_{m}\right) N_{A, i}^{-0.547}
$$

where $R m$ is the material tensile strength evaluated at room temperature. The reference stress range $\Delta \sigma_{\mathrm{r}}=\mathrm{fun}\left(\Delta \sigma, f_{s}, f_{t}, f_{p}\right)$ is calculated with consideration of surface and weld correction factor $f_{s}$, temperature correction factor $f_{t}$ and the plasticity correction factors $f_{p}$.

A stress safety factor of $s_{S}=1.5$ and a load-cycle safety factor $s_{L}=10$ shall be used to determine the $N_{A}$.

$$
N_{A}=\min \left(N_{A, S}, N_{A, L} / s_{L}\right)
$$


For the reference stress range $\Delta \sigma_{\mathrm{r}}, N_{A, S}$ shall be determined using eq S.12 with $\Delta \sigma_{r, S}=s_{S} \Delta \sigma_{r}$ and $N_{A, L}$ shall be determined using eq S.12 with $\Delta \sigma_{r, L}=\Delta \sigma_{r}$. 